\title{
Influence of Glibenclamide on Catecholamine Secretion in the Isolated Rat Adrenal Gland
}

\author{
Hae-Jeong No ${ }^{1,3}$, Seong-Chang $\mathrm{Woo}^{2}$, and Dong-Yoon Lim ${ }^{1 *}$ \\ ${ }^{1}$ Department of Pharmacology, College of Medicine, Chosun University, \\ Gwangju 501-759, KOREA; Department of ${ }^{2}$ Anesthesiology and \\ ${ }^{3}$ Family Medicine, Eulji University Hospital, Daejeon 302-120, KOREA
}

(Received 11 June 2007; Accepted 25 June 2007)

\begin{abstract}
The aim of the present study was to investigate the effect of glibenclamide, a hypoglycemic sulfonylurea, which selectively blocks ATP-sensitive $\mathrm{K}^{+}$channels, on secretion of catecholamines (CA) evoked by cholinergic stimulation and membrane depolarization from the isolated perfused rat adrenal glands. The perfusion of glibenclamide $(1.0 \mathrm{mM})$ into an adrenal vein for $90 \mathrm{~min}$ produced time-dependently enhanced the CA secretory responses evoked by $\mathrm{ACh}(5.32 \mathrm{mM})$, high $\mathrm{K}^{+}$(a direct membrane depolarizer, $56 \mathrm{mM}$ ), DMPP (a selective neuronal nicotinic receptor agonist, $100 \mu \mathrm{M}$ for $2 \mathrm{~min}$ ), McN-A-343 (a selective muscarinic $\mathrm{M}_{1}$ receptor agonist, 100 $\mu \mathrm{M}$ for $2 \mathrm{~min}$ ), Bay-K-8644 (an activator of L-type dihydropyridine $\mathrm{Ca}^{2+}$ channels, $10 \mu \mathrm{M}$ for $4 \mathrm{~min}$ ) and cyclopiazonic acid (an activator of cytoplasmic $\mathrm{Ca}^{2+}$-ATPase, $10 \mu \mathrm{M}$ for $4 \mathrm{~min}$ ). In adrenal glands simultaneously preloaded with glibenclamide $(1.0 \mathrm{mM})$ and nicorandil (a selective opener of ATP-sensitive $\mathrm{K}^{+}$channels, $1.0 \mathrm{mM}$ ), the CA secretory responses evoked by ACh, high potassium, DMPP, McN-A-343, Bay-K-8644 and cyclopiazonic acid were recovered to the considerable extent of the control release in comparison with that of glibenclamide-treatment only. Taken together, the present study demonstrates that glibenclamide enhances the adrenal CA secretion in response to stimulation of cholinergic (both nicotinic and muscarinic) receptors as well as by membrane depolarization from the isolated perfused rat adrenal glands. It seems that this facilitatory effect of glibenclamide may be mediated by enhancement of both $\mathrm{Ca}^{2+}$ influx and the $\mathrm{Ca}^{2+}$ release from intracellular store through the blockade of $\mathrm{K}_{\mathrm{ATP}}$ channels in the rat adrenomedullary chromaffin cells. These results suggest that glibenclamide-sensitive $\mathrm{K}_{\mathrm{ATP}}$ channels may play a regulatory role in the rat adrenomedullary CA secretion.
\end{abstract}

Keywords $\square$ Glibenclamide, Nicorandil, Catecholamine secretion, Adrenal gland, ATP-sensitive $\mathrm{K}^{+}\left(\mathrm{K}_{\text {ATP }}\right)$ channels

\section{INTRODUCTION}

Glibenclamide is known to inhibit competitively the vasorelaxant effects of UR-8225, which is a $\mathrm{K}_{\mathrm{ATP}}$-channel opener, in rat portal veins and aorta (Perez-Vizcaino et al., 1993). Asano and his coworkers (1994) have found that cromakalim causes arterial relaxation via the opening of $\mathrm{K}_{\mathrm{ATP}}$-channels in both SHR and Wistar-Kyoto rats, which is blocked by glibenclamide. $\mathrm{K}_{\mathrm{ATP}}$-channels are now established as octomeric proteins, consisting of four inward rectifier $\mathrm{K}^{+}$channel subunits associ-

\footnotetext{
*Corresponding author

Tel: $+82-62-230-6335, \quad$ Fax: $+82-62-227-4693$

E-mail: dylim@chosun.ac.kr

This paper was presented at the $21^{\text {st }}$ Scientific Meeting of the International Society of Hypertension (ISH) held in Fukuoka, Japan, October 15-19, 2006.
}

ated with four sulfonylurea receptors (SURs) (Aguilar-Bryan et al., 1998). SURs are the binding sites for known blockers (e.g., glibenclamide) and activators (e.g., pinacidil and cromakalim) of these channels, which have found valuable therapeutic uses. $\mathrm{K}_{\text {ATP }}$ channels are classically identified as being inhibited by intracellular ATP and were first described in cardiac myocytes (Noma, 1983) in which they were believed to act under conditions of metabolic stress to shorten action potential durations and so reduce the energy demands of myocytes when intracellular ATP levels are reduced (Benndorf et al., 1997).

In general, it has been shown that membrane $\mathrm{K}^{+}$channels in various cells are responsible for controlling the membrane potential and excitability of cells (Petersen \& Maruyama, 1984; Cook, 1988; Watson \& Abbott 1991). The opening (activation) of these channels causes hyperpolarization, and conversely, their closing (inhibition) causes depolarization of the cell mem- 
brane. Masuda and his coworkers (1994) found that in cultured bovine adrenal chormaffin cells, the $\mathrm{K}^{+}$channel openers, cromakalim and pinacidil, selectively inhibit the secretory responses of catecholamines (CA) induced by moderate depolarization or by stimulation of nicotinic acetylcholine (ACh) receptors. Wada and his coworkers (1987) have shown that the cultured bovine adrenal medullary cells have, at least, three distinct types of $\mathrm{K}^{+}$permeability mechanisms: (1) basal $\mathrm{K}^{+}$efflux, (2) $\mathrm{Ca}^{2+}$-dependent $\mathrm{K}^{+}$efflux, and (3) $\mathrm{Na}^{+}$-dependent $\mathrm{K}^{+}$ efflux, and that nicotinic receptors mediate $\mathrm{K}^{+}$efflux by increasing $\mathrm{Na}^{+}$influx via nicotinic receptor-associated ionic channels rather than $\mathrm{Ca}^{2+}$ influx via voltage-dependent $\mathrm{Ca}^{2+}$ channels.

ATP-sensitive potassium $\left(\mathrm{K}_{\mathrm{ATP}}\right)$-channels have been identified in numerous different tissues, including central neurons (Ashford et al., 1988; Murphy and Greenfield, 1992; Finta et al., 1993; Pierrefiche et al., 1996). Their role in the normal functioning of neuronal activity is not well established, but they have been shown to alter electrical excitability (primarily by causing membrane hyperpolarization when open) under hypoxic or ischemic conditions (Murphy and Greenfield, 1992; Wu et al., 1996). Evidence has emerged that $\mathrm{K}_{\mathrm{ATP}}$ channels may be active under normoxic conditions when intracellular ATP levels would not expected to be depleted (Pierrefiche et al., 1996). There is so far a little evidence about the influence of $\mathrm{K}_{\mathrm{ATP}}$-channels on the CA secretion from the perfused model of the isolated rat adrenal gland.

The aim of this study is to elucidate the functional role of $\mathrm{K}_{\mathrm{ATP}}$-channels in controlling the adrenal CA secretion. To this end, the present study was undertaken to examine the effects of glibenclamide, a selective $\mathrm{K}_{\mathrm{ATP}}$-channel blocker, on the CA secretion from the isolated perfused rat adrenal gland in response to the selective neuronal nicotinic receptor agonist 1,1-dimethyl-4-phenyl-piperazinium (DMPP), ACh, the selective muscarinic $\mathrm{M}_{1}$-receptor agonist $\mathrm{McN}-\mathrm{A}-343$, and the direct membrane-depolarizer high $\mathrm{K}^{+}$.

\section{MATERIALS AND METHODS}

\section{Experimental procedure}

Male Sprague-Dawley rats (supplied by Chosun University Center for Experimental Animals), weighing 180 to 300 grams, were anesthetized with thiopental sodium $(40 \mathrm{mg} / \mathrm{kg}$ ) intraperitoneally. The adrenal gland was isolated by some modification of the methods described previously (Wakade, 1981). The abdomen was opened by a midline incision, and the left adrenal gland and surrounding area were exposed by the placement of three-hook retractors. The stomach, intestine and portion of the liver were not removed, but pushed over to the right side and covered by saline-soaked gauge pads and urine in bladder was removed in order to obtain enough working space for tying blood vessels and cannulations.

A cannula, used for perfusion of the adrenal gland, was inserted into the distal end of the renal vein after all branches of adrenal vein (if any), vena cava and aorta were ligated. Heparin (400 IU/ml) was injected into vena cava to prevent blood coagulation before ligating vessels and cannulations. A small slit was made into the adrenal cortex just opposite entrance of adrenal vein. Perfusion of the gland was started, making sure that no leakage was present, and the perfusion fluid escaped only from the slit made in adrenal cortex. Then the adrenal gland, along with ligated blood vessels and the cannula, was carefully removed from the animal and placed on a platform of a leucite chamber. The chamber was continuously circulated with water heated at $37 \pm 1^{\circ} \mathrm{C}$.

\section{Perfusion of adrenal gland}

The adrenal glands were perfused by means of peristaltic pump (ISCO, WIZ Co., U.S.A.) at a rate of $0.33 \mathrm{ml} / \mathrm{min}$. The perfusion was carried out with Krebs-bicarbonate solution of following composition (mM): $\mathrm{NaCl}, 118.4 ; \mathrm{KCl}, 4.7 ; \mathrm{CaCl}_{2}$, 2.5; $\mathrm{MgCl}_{2}, 1.18 ; \mathrm{NaHCO}_{3}, 25 ; \mathrm{KH}_{2} \mathrm{PO}_{4}, 1.2 ;$ glucose, 11.7. The solution was constantly bubbled with $95 \% \mathrm{O} 2+5 \% \mathrm{CO} 2$ and the final $\mathrm{pH}$ of the solution was maintained at 7.4 7.5. The solution contained disodium EDTA $(10 \mu \mathrm{g} / \mathrm{ml})$ and ascorbic acid $(100 \mu \mathrm{g} / \mathrm{ml})$ to prevent oxidation of CA.

\section{Drug administration}

The perfusions of DMPP $\left(10^{-4} \mathrm{M}\right)$ for 2 minutes and/or a single injection of $\mathrm{ACh}\left(5.32 \times 10^{-3} \mathrm{M}\right)$ and $\mathrm{KCl}\left(5.6 \times 10^{-2} \mathrm{M}\right)$ in a volume of $0.05 \mathrm{ml}$ were made into perfusion stream via a threeway stopcock, respectively. McN-A-343 (10-4 M), Bay-K-8644 $\left(10^{-5} \mathrm{M}\right)$ and cyclopiazonic acid $\left(10^{-5} \mathrm{M}\right)$ were also perfused for $4 \mathrm{~min}$, respectively.

In the preliminary experiments, it was found that upon administration of the above drugs, secretory responses to ACh, $\mathrm{KCl}$, McN-A-343, Bay-K-8644 and cyclopiazonic acid returned to pre-injection level in about $4 \mathrm{~min}$, but the responses to DMPP in $8 \mathrm{~min}$.

\section{Collection of perfusate}

As a rule, prior to stimulation with various secretagogues, 
the perfusate was collected for 4 min to determine the spontaneous secretion of CA (background sample). Immediately after the collection of the background sample, collection of the perfusates was continued in another tube as soon as the perfusion medium containing the stimulatory agent reached the adrenal gland. Stimulated sample's was collected for 4 to $8 \mathrm{~min}$. The amounts secreted in the background sample have been subtracted from that secreted from the stimulated sample to obtain the net secretion value of CA, which is shown in all of the figures.

To study the effect of glibenclamide on the spontaneous and evoked secretion, the adrenal gland was perfused with Krebs solution containing glibenclamide for $90 \mathrm{~min}$, and then the perfusate was collected for a certain period (background sample). Then the medium was changed to the one containing the stimulating agent or along with glibenclamide, and the perfusates were collected for the same period as that for the background sample. The adrenal gland's perfusate was collected in chilled tubes.

\section{Measurement of catecholamines}

CA content of perfusate was measured directly by the fluorometric method of Anton and Sayre (Anton and Sayre, 1962) without the intermediate purification alumina for the reasons described earlier (Wakade, 1981) using fluorospectrophotometer (Kontron Co., Milano, Italy).

A volume of $0.2 \mathrm{ml}$ of the perfusate was used for the reaction. The CA content in the perfusate of stimulated glands by secretagogues used in the present work was high enough to obtain readings several folds greater than the reading of control samples (unstimulated). The sample blanks were also lowest for perfusates of stimulated and non-stimulated samples. The content of CA in the perfusate was expressed in terms of norepinephrine (base) equivalents.

\section{Drugs and their sources}

The following drugs were used: nicorandil (Choong Wae Pharma. Corp., Korea), glibenclamide, acetylcholine chloride, 1.1-dimethyl-4-phenyl piperazinium iodide (DMPP), norepinephrine bitartrate, methyl-1, 4-dihydro-2,6-dimethyl-3-nitro4-(2-trifluoromethyl-phenyl)-pyridine-5-carboxylate (Bay-K8644) (Sigma Chemical Co., U.S.A.), and cyclopiazonic acd, (3(m-cholro-phenyl-carbamoyl-oxy)-2-butynyltrimethyl ammonium chloride [McN-A-343] (RBI, U.S.A.). Drugs were dissolved in distilled water (stock) and added to the normal Krebs solution as required except Bay-K-8644 and nicorandil, which were dissolved in $99.5 \%$ ethanol and $99.5 \%$ dimethyl sulfoxide (DMSO), respectively, and diluted appropriately with Krebsbicarbonate solution (final concentration of alcohol or DMSO was less than $0.1 \%$ ). Concentrations of all drugs used are expressed in terms of molar base.

\section{Statistical analysis}

The statistical difference between the control and pretreated groups was determined by the Student's paired $t$-test. A P-value of less than 0.05 was considered to represent statistically significant changes unless specifically noted in the text. Values given in the text refer to means and the standard errors of the mean (S.E.M.). The statistical analysis of the experimental results was made by computer program described by Tallarida and Murray (1987).

\section{RESULTS}

\section{Effect of glibenclamide on $\mathrm{CA}$ release evoked by $\mathrm{ACh}$, high $\mathrm{K}^{+}$, DMPP and McN-A-343 from the perfused rat adrenal medulla}

After the perfusion with oxygenated Krebs-bicarbonate solution for $1 \mathrm{hr}$, basal CA release from the isolated perfused rat adrenal glands amounted to $21 \pm 2 \mathrm{ng}$ for $2 \mathrm{~min}(\mathrm{n}=6)$ in all groups. There were no significant differences in these basal values among the experimental groups. glibenclamide is known to inhibit competitively the vasorelaxant effects of UR-8225, which is a $\mathrm{K}_{\mathrm{ATP}}$-channel opener, in rat portal veins and aorta (Perez-Vizcaino et al., 1993). Therefore, it was attempted initially to examine the effects of glibenclamide itself on CA secretion from the perfused model of the rat adrenal glands. In the present study, In 6 rat adrenal glands, glibenclamide-evoked CA secretory response was maximally about $80 \mathrm{ng}(0 \sim 60 \mathrm{~min})$, which seemed to be a very weak secretagogue. Therefore, in the subsequent experiments, the time course effects of glibenclamide on the CA seretory responses evoked by $\mathrm{ACh}$, high $\mathrm{K}^{+}$, DMPP and McN-A-343 were examined. Secretagogues were given at 15 to 20 min-intervals. Glibenclamide was present for 90 minutes after the establishment of the control release to secretagogues.

When ACh $(5.32 \mathrm{mM})$ in a volume of $0.05 \mathrm{ml}$ was injected into the perfusion stream, the amount of CA secreted was $384 \pm$ $13 \mathrm{ng}$ for $4 \mathrm{~min}$. However, the pretreatment with $1.0 \mathrm{mM}$ glibenclamide for $90 \mathrm{~min}$ relatively time-dependently enhanced ACh-stimulated CA secretion. As shown in Fig. 1 (Upper), in the presence of glibenclamide, CA-releasing response was 
enhanced to $120 \%$ of the corresponding control release, but not affected at 0-34 min period. Also, it has been found that depolarizing agent like $\mathrm{KCl}$ stimulates markedly CA secretion (166 $\pm 10 \mathrm{ng}$ for $0-4 \mathrm{~min})$. High $\mathrm{K}^{+}(56 \mathrm{mM})$-stimulated CA secretion after the pretreatment with $1.0 \mathrm{mM}$ glibenclamide was not affected for about $50 \mathrm{~min}$ as compared with its corresponding control secretion (100\%) (Fig. 1-Lower). However, in 60-94
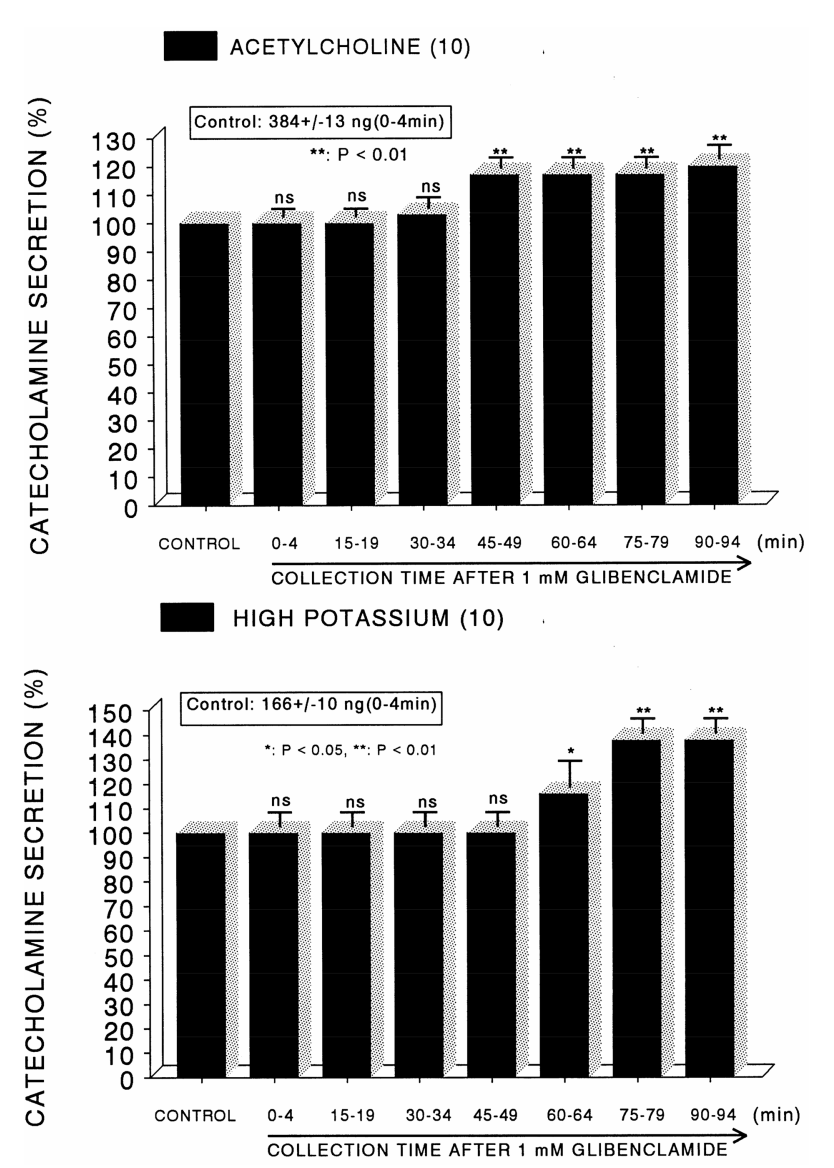

Fig. 1. Time-course effect of glibenclamide on the secretory responses of catecholamines (CA) evoked by acetylcholine (ACh, Upper) and by high $\mathrm{K}^{+}$(Lower) from the isolated perfused rat adrenal glands. CA secretion by a single injection of ACh $(5.32 \mathrm{mM})$ or $\mathrm{K}^{+}(56 \mathrm{mM})$ in a volume of $0.05 \mathrm{ml}$ was evoked at 15 min intervals after preloading with $1.0 \mathrm{mM}$ glibenclamide for $90 \mathrm{~min}$ as indicated at an arrow mark. Numbers in the parenthesis indicate number of rat adrenal glands. Vertical bars on the columns represent the standard error of the mean (S.E.M.). Ordinate: the amounts of CA secreted from the adrenal gland ( $\%$ of control). Abscissa: collection time of perfusate $(\mathrm{min})$. Statistical difference was obtained by comparing the corresponding control (CONT) with each concentration-pretreated group of glibenclamide. Pefusates induced by $\mathrm{ACh}$ and high $\mathrm{K}^{+}$were collected for 4 minutes, respectively. $*: \mathrm{P}<0.05,{ }^{*}: \mathrm{P}<0.01$. ns: Statistically not significant. min period, it was greatly enhanced to $138 \%$ of the control release. DMPP $(100 \mu \mathrm{M})$, which is a selective nicotinic receptor agonist in autonomic sympathetic ganglia, evoked a sharp and rapid increase in CA secretion (346 $\pm 10 \mathrm{ng}$ for 0-8 $\mathrm{min}$ ). However, as shown in Fig. 2 (Upper), DMPP-stimulated CA secretion after pretreatment with glibenclamide was increased to $122 \%$ of the control release $(100 \%)$. McN-A-343 $(100 \mu \mathrm{M})$, which is a selective muscarinic M1-agonist (Hammer and Giachetti, 1982), perfused into an adrenal gland for 4 min caused an increased CA secretion (172 $\pm 9 \mathrm{ng}$ for 0-4 min). However, McN-A-343-stimulated CA secretion in the presence of glibenclamide was markedly enhanced to $136 \%$ of the correspond-

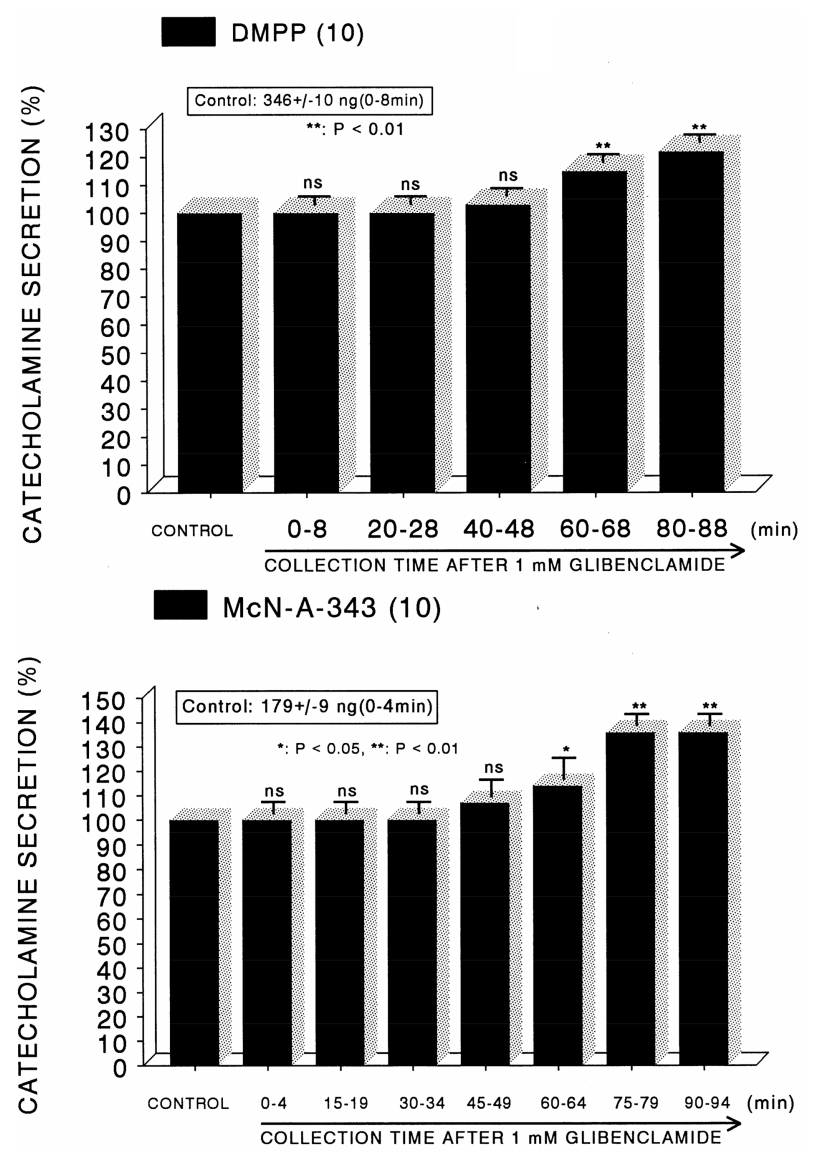

Fig. 2. Time-course effect of glibenclamide on the secretory responses of catecholamines (CA) evoked by DMPP (Upper) and McN-A-343 (Lower) from the isolated perfused rat adrenal glands. The CA secretory responses by the perfusion of DMPP $(100 \mu \mathrm{M})$ and McN-A-343 $(100 \mu \mathrm{M})$ for 2 min at 20 and $15 \mathrm{~min}$ intervals were induced after preloading with 1.0 $\mathrm{mM}$ glibenclamide for $90 \mathrm{~min}$, respectively. Pefusates induced by DMPP and McN-A-343 were collected for 8 and 4 minutes, respectively. Other legends are the same as in Fig. 1. *: $\mathrm{P}<$ $0.05, * *: \mathrm{P}<0.01$. ns: Statistically not significant. 
ing control secretion (100\%), although it was not affected at 049 min period, as depicted in Fig. 2 (Lower)

Effect of glibenclamide on CA release evoked by Bay-K8644 and cyclopiazonic acid from the perfused rat adrenal medulla

Since Bay-K-8644 is known to be a calcium channel activator, which enhances basal $\mathrm{Ca}^{2+}$ uptake (Garcia et al., 1984) and CA release (Lim et al., 1992), it was of interest to determine the effects of glibenclamide on Bay-K-8644-stimulated CA secretion from the isolated perfused rat adrenal glands. Bay-K-8644 $(10 \mu \mathrm{M})$-stimulated CA secretion in the presence of glibenclamide was greatly elevated to $141 \%$ of the control except for

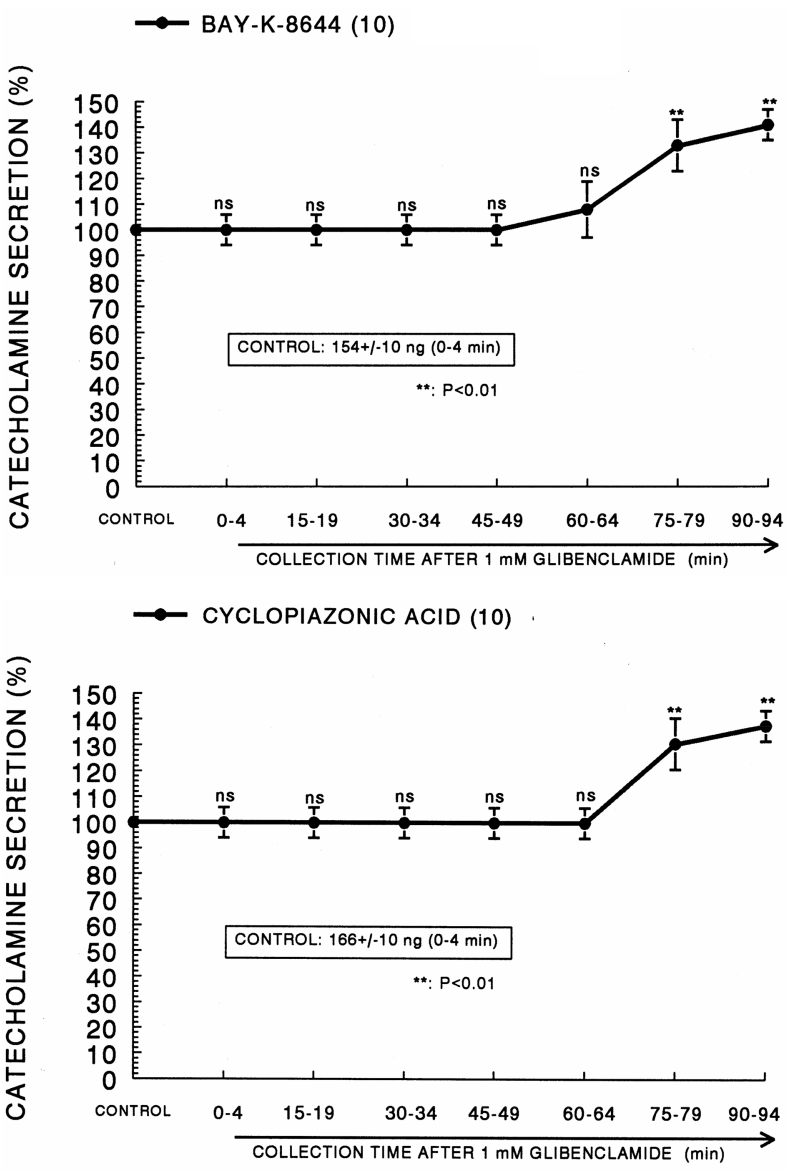

Fig. 3. Time-course effect of glibenclamide on CA release evoked by Bay-K-8644 (Upper) and cyclopiazonic acid (Lower) from the rat adrenal glands. Bay-K-8644 $(10 \mu \mathrm{M})$ and cyclopiazonic acid $(10 \mu \mathrm{M})$ were perfused into an adrenal vein for $4 \mathrm{~min}$ at $15 \mathrm{~min}$ intervals after preloading with of glibenclamide $(1.0 \mathrm{mM})$ for $90 \mathrm{~min}$, respectively. Other legends are the same as in Fig. 1. **: $\mathrm{P}<0.01$. ns: Statistically not significant. early $45 \mathrm{~min}$ as compared to the corresponding control release (154 $\pm 10 \mathrm{ng}$ for 0-4 min) from 10 rat adrenal glands, as shown in Fig. 3 (Upper).

Cyclopiazonic acid, a mycotoxin from Aspergillus and Penicillium, has been described as a highly selective inhibitor of $\mathrm{Ca}^{2+}$-ATPase in skeletal muscle sarcoplasmic reticulum (Goeger and Riley, 1989; Seidler et al., 1989). The inhibitory action of glibenclamide on cyclopiazonic acid-evoked CA secretory response was observed as shown in Fig. 3 (Lower). However, in the presence of glibenclamide in 10 rat adrenal glands, cyclopiazonic acid $(10 \mu \mathrm{M})$-evoked CA secretion was also elevated to $138 \%$ of the control response $(166 \pm 10 \mathrm{ng}$ for 0 $4 \mathrm{~min})$.

Effect of glibenclamide plus nicorandil on $\mathrm{CA}$ release evoked by ACh, high $\mathrm{K}^{+}$, DMPP, McN-A-343, BAY-K8644 and cyclopiazonic acid from the perfused rat adrenal glands

As shown in Fig. 1 2, glibenclamide significantly enhanced the CA secretory responses evoked by cholinergic stimulation and membrane depolarization form the perfused rat adrenal glands. Nicorandil has at least two mechanisms of action; This drug relaxes vascular smooth muscle by stimulating soluble guanylate cyclase leading to increased cGMP levels (Endo and Taira, 1983; Holzmann, 1983; Meisheri et al., 1991) and also opening of ATP-sensitive $\mathrm{K}^{+}\left(\mathrm{K}_{\mathrm{ATP}}\right)$ channels to hyperpolarize the plasma membrane (Furukawa et al., 1981: Kukovetz et al., 1991; Holzmann et al, 1992). Therefore, in the presence of glibenclamide $(1.0 \mathrm{mM})$, the effect of nicornadil on the CA secretion evoked by cholinergic stimulation and membranedepolarization in the perfused rat adrenal medulla was examined.

In the present study, ACh $(5.32 \mathrm{mM})$-evoked CA release before perfusion with nicorandil plus glibenclamide was $358 \pm$ $10 \mathrm{ng}(0-4 \mathrm{~min})$ from 10 rat adrenal glands. In the simultaneous presence of nicorandil $(1.0 \mathrm{mM})$ and glibenclamide $(1.0 \mathrm{mM})$ for $90 \mathrm{~min}$, it was initially not affected at 0-64 min, but later rather inhibited by $82 \%$ of the corresponding control release at 90-94 min period as illustrated in Fig. 4 (Upper). High $\mathrm{K}^{+}$(56 $\mathrm{mM}$ )-evoked CA release in the presence of nicorandil (1.0 $\mathrm{mM})$ and glibenclamide $(1.0 \mathrm{mM})$ for $90 \mathrm{~min}$ was also not changed for 0-64 min, but later inhibited to $74 \%$ of the corresponding control release only at the last period of 90-94 min period in comparison to the control secretion (179 $\pm 9 \mathrm{ng}, 0-4$ $\mathrm{min}$ ) from 10 glands (Fig. 4-Lower).

As shown in Fig. 5 (Upper), DMPP-evoked CA release prior 


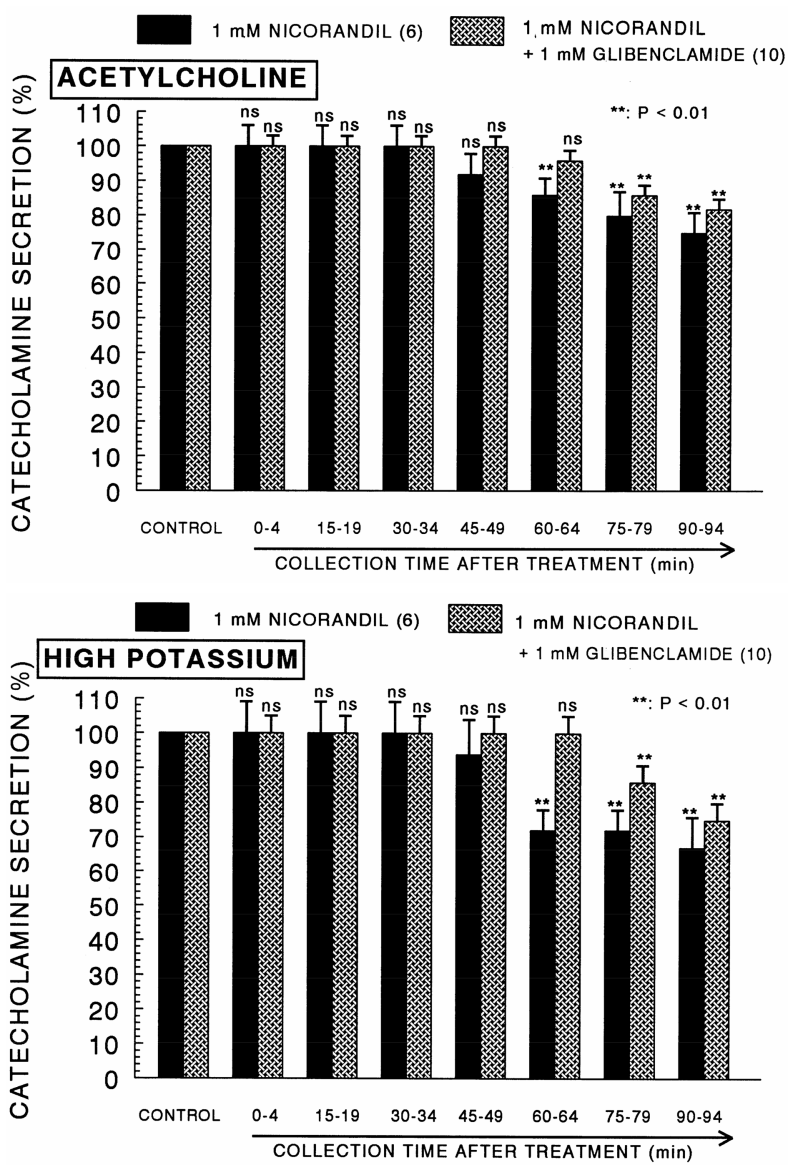

Fig. 4. Effects of glibenclamide plus nicorandil on catecholamine release evoked by acetylcholine (upper) and high $\mathrm{K}^{+}$(lower) from the isolated perfused rat adrenal glands. CA secretion by a single injection of Ach $(5.32 \mathrm{mM})$ or high $\mathrm{K}^{+}(56 \mathrm{mM})$ was induced "BEFORE (CONTROL)" and "AFTER" preloading simultaneously with $1.0 \mathrm{mM}$ nicorandil $+1.0 \mathrm{mM}$ glibenclamide for $90 \mathrm{~min}$, respectively. Other legends are the same as in Fig. 1. **: $\mathrm{P}<0.01$. ns: Statistically not significant.

to simultaneous perfusion with nicorandil and glibenclamide was $371 \pm 16 \mathrm{ng}(0-8 \mathrm{~min})$. The simultaneous perfusion of nicorandil and glibenclamide for $90 \mathrm{~min}$ no longer inhibited DMPP-evoked CA release for the period of 0-68 $\mathrm{min}$ from 10 experiments while later rather depressed to $85 \%$ of the control release at $80-88 \mathrm{~min}$ period. Moreover, in the presence of both nicorandil $(1.0 \mathrm{mM})$ and glibenclamide $(1.0 \mathrm{mM})$, the CA secretory response evoked by McN-A-343 (10 $-4 \mathrm{M}$ for $4 \mathrm{~min})$ was also not affected for 0-64 $\mathrm{min}$, but later rather inhibited to $75 \%$ of the corresponding control release (179 $\pm 9 \mathrm{ng}, 0-4 \mathrm{~min}$ ) at the last period of 90-94 min period from 10 glands, as shown in Fig. 5 (Lower).

As shown in Fig. 6, the simultaneous perfusion of nicorandil $(1.0 \mathrm{mM})$ and glibenclamide $(1.0 \mathrm{mM})$ for $90 \mathrm{~min}$ did not

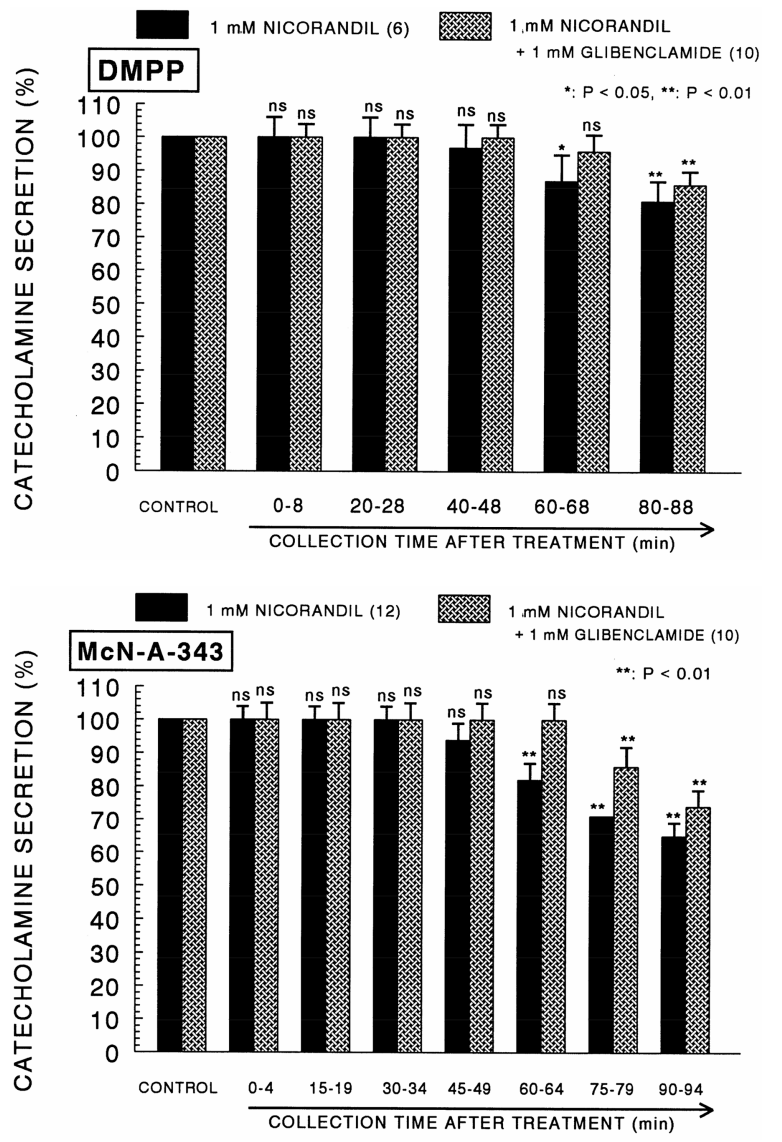

Fig. 5. Effects of glibenclamide plus nicorandil on catecholamine release evoked by DMPP (Upper) and McN-A-343 (Lower) from the isolated perfused rat adrenal glands. The CA secretory responses by the perfusion of DMPP $(100 \mu \mathrm{M})$ and McN-A$343(100 \mu \mathrm{M})$ for $2 \mathrm{~min}$ and $4 \mathrm{~min}$ at 20 and $15 \mathrm{~min}$ intervals were induced "BEFORE (CONTROL)" and "AFTER" preloading simultaneously with $1.0 \mathrm{mM}$ nicorandil $+1.0 \mathrm{mM}$ glibenclamide for $90 \mathrm{~min}$, respectively. Other legends are the same as in Fig. 1. *: $\mathrm{P}<0.05, * *: \mathrm{P}<0.01$. ns: Statistically not significant.

inhibit the CA release evoked by Bay-K-644 (Upper) and cyclopiazonic acid (Lower) for the period of 0-79 $\mathrm{min}$ from 10 experiments, but later rather depressed to $72 \%$ and $79 \%$ of each control release only at 90-94 min period in comparison to their corresponding control responses (179 $\pm 9 \mathrm{ng}, 0-4 \mathrm{~min}$ and $181 \pm 7$ ng, 0-4 min), respectively.

\section{DISCUSSION}

The present experimental results demonstrate that glibenclamide enhances the adrenal CA secretion in response to stimulation of cholinergic (both nicotinic and muscarinic) receptors as well as by membrane depolarization from the isolated perfused rat adrenal glands. 


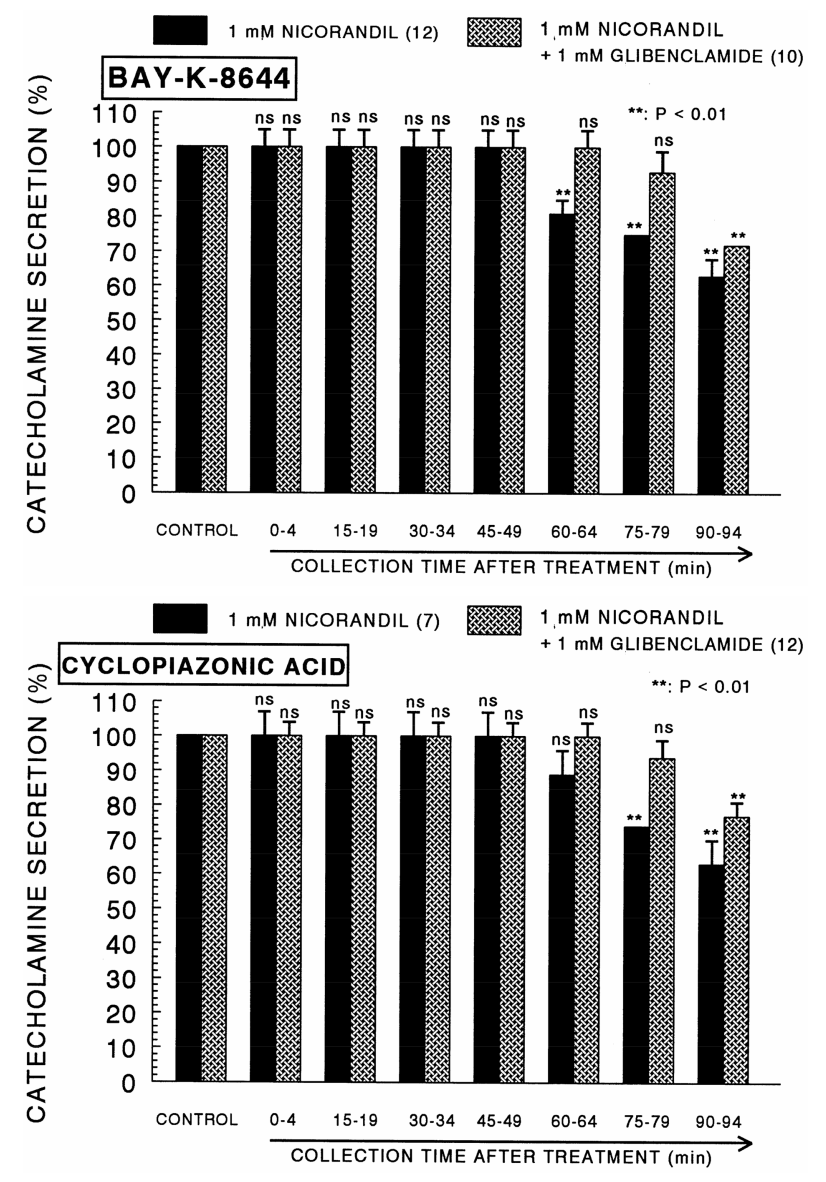

Fig. 6. Effects of glibenclamide plus nicorandil on catecholamine release evoked by Bay-K-8644 (Upper) and cyclopiazonic acid (Lower) from the rat adrenal glands. Bay$\mathrm{K}-8644(10 \mu \mathrm{M})$ and cyclopiazonic acid $(10 \mu \mathrm{M})$ were perfused into an adrenal vein for $4 \mathrm{~min}$ at $15 \mathrm{~min}$ intervals "BEFORE (CONTROL)" and "AFTER" preloading simultaneously with $1.0 \mathrm{mM}$ nicorandil $+1.0 \mathrm{mM}$ glibenclamide for $90 \mathrm{~min}$, respectively. Other legends are the same as in Fig. 1. **: $\mathrm{P}<$ 0.01. ns: Statistically not significant.

In the present work, glibenclamide, which selectively blocks ATP-sensitive $\mathrm{K}^{+}$channels (Quast \& Cook, 1989; Ashcroft, 1988), restored the inhibitory responses by nicorandil on the CA secretion evoked by ACh, DMPP, McN-A-343 and high potassium to the considerable extent of the corresponding control level. These findings suggest strongly that ATP-sensitive $\mathrm{K}^{+}$channels are involved in regulating the CA secretion in the rat adrenal medullary chromaffin cells. In support of this idea, it has been shown that $\mathrm{K}_{\mathrm{ATP}}$-channel openers, such as cromakalim, pinacidil, and nicorandil, produce vasorelaxation by preventing the opening of voltage-activated $\mathrm{Ca}^{2+}$ channels through the opening of $\mathrm{K}_{\mathrm{ATP}}$-channels and the resulting membrane hyperpolarization (Cook, 1988; Hamilton \& Weston,
1989; Weston, 1988; Standen et al., 1989; Quast \& Cook, 1989; Weston et al., 1990; Edwards et al., 1992). Moreover, glibenclamide is known to inhibit competitively the vasorelaxant effects of UR-8225, which is a $\mathrm{K}_{\mathrm{ATP}}$-channel opener, in rat portal veins and aorta (Perez-Vizcaino et al., 1993). Asano and his coworkers (1994) have found that cromakalim causes arterial relaxation via the opening of $\mathrm{K}_{\mathrm{ATP}}$-channels in both SHR and Wistar-Kyoto rats, which is blocked by glibenclamide. In terms of these findings, the present results indicate that glibenclamide may enhance the CA secretory responses at least through blockade of $\mathrm{K}_{\mathrm{ATP}}$-channels located on the rat adrenomedullary chromaffin cells. $\mathrm{K}_{\mathrm{ATP}}$-channels are now established as octomeric proteins, consisting of four inward rectifier $\mathrm{K}^{+}$ channel subunits associated with four sulfonylurea receptors (SURs) (Aguilar-Bryan et al., 1998). SURs are the binding sites for known blockers (e.g., glibenclamide) and activators (e.g., pinacidil and cromakalim) of these channels, which have found valuable therapeutic uses. $\mathrm{K}_{\mathrm{ATP}}$ channels are classically identified as being inhibited by intracellular ATP and were first described in cardiac myocytes (Noma, 1983) in which they were believed to act under conditions of metabolic stress to shorten action potential durations and so reduce the energy demands of myocytes when intracellular ATP levels are reduced (Benndorf et al., 1997).

In the present work, in the presence of glibenclamide, the CA exocytosis evoked by both high $\mathrm{K}^{+}$and Bay-K-8644 was clearly enhanced and this facilitatory effect is prevented in the simultaneous presence of glibenclamide and nicorandil. Based on these results, it seems that glibenclamide enhances the CA secretion partly through SUR-mediated action. This action of glibenclamide is very similar with previous result as shown by pinacidil (Lim et al., 2000), although two agents are structurally distinct activators of $\mathrm{K}_{\text {ATP }}$ In neuronal tissue, kromakalim and pinacidil agents are also known to reverse the effects of glibenclamide (Schmid-Antomarchi et al., 1990). This evidence leads to conclusion that a novel role for SUR in modulating exocytosis in a neuronal tissue is identified. Furthermore, these findings would suggest that this role is functionally downstream of $\mathrm{Ca}^{2+}$ entry or mobilization. However, more detailed mechanism of action on the CA secretory effects of nicorandil and glibenclamide remains to be resolved in future.

Generally, the CA secretion from the adrenal medulla is controlled by splanchnic nerve-innervated chromaffin cells. Activation of the splanchnic nerve causes the release of acetylcholine ( $\mathrm{ACh}$ ) from its terminal into the intrasynaptic cleft, which subsequently activates nicotinic receptors of the 
adrenal medullary chromaffin cells. Stimulation of nicotinic receptors depolarizes the chromaffin cell membrane, and the resulting depolarization causes $\mathrm{Ca}^{2+}$ influx through the opening of voltage-dependent $\mathrm{Ca}^{2+}$ channels (Cena et al., 1983; Corcoran and Kirshner, 1983). The elevation of intracellular $\mathrm{Ca}^{2+}$ triggers the exocytotic secretion of adrenal CA (Garcia et al., 1984). The membrane depolarization may activate voltagedependent $\mathrm{K}^{+}$channels, leading to the facilitation of repolarization, and the elevation of intracellular $\mathrm{Ca}^{2+}$ may activate $\mathrm{Ca}^{2+}$ activated $\mathrm{K}^{+}$channels, leading to hyperpolarization. The facilitation of repolarization or hyperpolarization may cause the inhibition of further influx of $\mathrm{Ca}^{2+}$. Therefore, blockade of $\mathrm{K}^{+}$ channels is thought to facilitate the depolarizing phase and results in the enhancement of adrenal CA secretion through the increase in $\mathrm{Ca}^{2+}$ influx.

In the present study, the finding that both nicorandil inhibited the CA secretory responses evoked by stimulation of nicotinic ACh receptors with DMPP and membrane depolarization with high $\mathrm{K}^{+}$seems to be very similar to that obtained in cultured bovine adrenal chromaffin cells (Masuda et al., 1994). In cultured bovine chromaffin cells, Masuda and his coworkers (1994) found that cromakalim and pinacidil inhibit the CA release, ${ }^{45} \mathrm{Ca}^{2+}$ influx and increase in intracellular $\mathrm{Ca}^{2+}$ induced by moderate depolarization by potassium as well as by stimulation of nicotinic receptors with carbamylcholine. Based on this finding, the present data indicate that the $\mathrm{K}_{\mathrm{ATP}}$-channel opener like nicorandil affects membrane potassium channels, resulting in an increase in $\mathrm{K}^{+}$efflux and then a decrease in the CA secretion from rat adrenal chromaffin cells. In the present work, nicorandil inhibited the CA secretion evoked by $\mathrm{ACh}$, high $\mathrm{K}^{+}$, DMPP and McN-A-343. However, in the presence of glibenclamide, nicorandil-induced inhibitory effect of the CA secretion was recovered to the considerable extent of the corresponding control release in comparison with that by nicorandiltreatment only. These results are consistent with the observation with pinacidil, another $\mathrm{K}_{\mathrm{ATP}}$ channel activator in the perfused rat adrenal medulla (Lim et al., 2000), indicating that nicorandil suppresses the CA secretion by affecting pathways mediated by both nicotinic and muscarinic receptors but that it does not inhibit the secretion process by itself.

It has been shown that muscarinic stimulation generates a depolarizing signal which triggers the firing of action potentials, resulting in the increased CA release in the rat chromaffin cells (Akaike et al, 1990; Lim \& Hwang, 1991). These observations are in line with a previous report (Ladona et al., 1987; Uceda et al., 1992) showing that Bay-K-8644 almost tripled the peak secretory response to muscarine in perfused $\mathrm{Ca}^{2+}$ cat adrenal glands. In this experiment, both nicorandil also depress greatly the CA secretion induced by Bay-K-8644, which is found to enhance the $\mathrm{CA}$ release by increasing $\mathrm{Ca}^{2+}$ influx through L-type $\mathrm{Ca}^{2+}$ channels in chromaffin cells (Garcia et al., 1984). These findings that nicorandil inhibited the CA secretion evoked by high $\mathrm{K}^{+}$and also by Bay-K-8644 suggest that nicorandil inhibits directly the voltage-dependent $\mathrm{Ca}^{2+}$ channels through opening of $\mathrm{K}^{+}$channels, just like $\mathrm{Ca}^{2+}$ channel blockers (Cena et al., 1983), which have direct actions on voltage-dependent $\mathrm{Ca}^{2+}$ channels. In the bovine chromaffin cells, stimulation of nicotinic, but not muscarinic ACh receptors is known to cause the $\mathrm{CA}$ secretion by increasing $\mathrm{Ca}^{2+}$ influx largely through voltage-dependent $\mathrm{Ca}^{2+}$ channels (Burgoyne, 1984; Oka et al., 1979). Therefore, it seems that nicorandil inhibits DMPP-evoked CA secretion by inhibiting $\mathrm{Ca}^{2+}$ influx through voltage-dependent $\mathrm{Ca}^{2+}$ channels activated by nicotinic ACh receptors with DMPP. However, Masuda and his coworkers (1994) found that cromakalim and pinacidil did not affect the CA secretion from the cultured bovine chromaffin cells induced by Bay-K-8644 (Garcia et al., 1984) or $\mathrm{Ba}^{2+}$ (Terbush \& Holz, 1992; Heldman et al., 1989), suggesting that they did not inhibit influx of $\mathrm{Ca}^{2+}$ induced by an opener of L-type voltage-sensitive $\mathrm{Ca}^{2+}$ channels such as Bay-K-8644, or influx of $\mathrm{Ba}^{2+}$, which is thought to pass through voltage-sensitive $\mathrm{Ca}^{2+}$ channels and to stimulate the CA secretion.

In this study, nicorandil inhibited the increase in the CA secretion evoked by cyclopiazonic acid, which is known to be a highly selective inhibitor of $\mathrm{Ca}^{2+}$-ATPase in skeletal muscle sarcoplasmic reticulum (Goeger \& Riley, 1989; Seidler et al., 1989) and a valuable pharmacological tool for investigating intracellular $\mathrm{Ca}^{2+}$ mobilization and ionic currents regulated by intracellular $\mathrm{Ca}^{2+}$ (Suzuki et al., 1992). Therefore, these results suggest that the inhibitory effect of nicorandil on the CA secretion evoked by cholinergic muscarinic stimulation might be associated with the mobilization of intracellular $\mathrm{Ca}^{2+}$ in the chromaffin cells. This indicates that the $\mathrm{K}_{\mathrm{ATP}}$ channel opener has an inhibitory effect on the release of $\mathrm{Ca}^{2+}$ from the intracellular pools induced by stimulation of muscarinic ACh receptors, which is weakly responsible for the CA secretion. It has been shown that $\mathrm{Ca}^{2+}$-uptake into intracellular storage sites susceptible to caffeine (Ilno, 1989) is almost completely abolished by treatment with cyclopiazonic acid during the proceeding $\mathrm{Ca}^{2+}$ load (Suzuki et al., 1992). This is consistent with the findings obtained in skinned smooth muscle fibers of the logitudinal layer of the guinea-pig ileum, where $\mathrm{Ca}^{2+}$-uptake was also 
inhibited by cylopiazonic acid (Uyama et al., 1992). Suzuki and his coworkers (1992) have shown that cyclopiazonic acid easily penetrates into the cytoplasm through the plasma membrane and reduces $\mathrm{Ca}^{2+}$-ATPase activity in sarcoplasmic/endoplasmic reticulum, resulting in increase in the subsequent $\mathrm{Ca}^{2+}$ release from those storage sites and thereby increase of $\mathrm{Ca}^{2+}$ dependent $\mathrm{K}^{+}$-current. Moreover, in bovine adrenal chromaffin cells, stimulation of muscarinic ACh receptors is also proposed to cause activation of phosphoinositide metabolism, resulting in the formation of inositol 1,4,5-trisphosphate, which induces the mobilization of $\mathrm{Ca}^{2+}$ from the intracellular pools (Cheek et al., 1989; Challis et al., 1991). However, in the present study, it is uncertain whether the inhibitory effect of the $\mathrm{K}_{\text {ATP }}$ channel opener on $\mathrm{Ca}^{2+}$ movement from intracellular pools is due to their direct effect on the PI response or an indirect effect as a result of the membrane hyperpolarization induced by opening of $\mathrm{K}_{\mathrm{ATP}}$ channels.

In conclusion, the present study demonstrates that glibenclamide enhances the adrenal CA secretion in response to stimulation of cholinergic (both nicotinic and muscarinic) receptors as well as by membrane depolarization from the isolated perfused rat adrenal glands. It seems that this facilitatory effect of glibenclamide may be mediated by enhancement of both $\mathrm{Ca}^{2+}$ influx and the $\mathrm{Ca}^{2+}$ release from intracellular store through the blockade of $\mathrm{K}_{\text {ATP }}$ channels in the rat adrenomedullary chromaffin cells. These results suggest that glibenclamide-sensitive $\mathrm{K}_{\text {ATP }}$ channels may play a regulatory role in the rat adrenomedullary CA secretion.

\section{REFERENCES}

Akaike, A., Mine, Y., Sasa, M. and Takaori, S. (1990). Voltage and current clamp studies of muscarinic and nicotinic excitation of the rat adrenal chromaffin cells. J. Pharmacol. Expt. Ther. 255, 333-339.

Anton, A. H. and Sayre, D. F. (1962). A study of the factors affecting the aluminum oxidetrihydroxy indole procedure for the analysis of catecholamines. J. Pharmacol. Exp. Ther. 138, 360-375

Aguilar-Bryan, L., Clement, J. P., Gonzalez, G., Kunjilwar, K., Babenko, A. and Bryan, J. (1998). Toward understanding the assembly and structure of $\mathrm{K}_{\text {ATP }}$ channels. Physiol. Rev. 78, 227-245.

Asano, M., Masuzawa-Ito, K. and Matsuda, T. (1994). Vasodilating actions of cromakalim in resting and contracting states of carotid arteries from spontaneously hypertensive rats. European J. Pharmacol. 263, 121-131.

Ashcroft, F. M. (1988). Adenosine 5'-triphosphate-sensitive potassium channels. Annu. Rev. Neurosci. 11, 763-770.

Ashford, M. L. J., Sturgess, N. C., Trout, N. J., Gardner, N. J. and Hales, C. N. (1988). Adenosine 5'-triphosphate-sensitive ion chan- nels in neonatal rat cultured central neurones. Pflügers Arch. 412, 297-304.

Benndorf, K., Thierfelder, S., Doepner, B., Gebhardt, C. and Hirche, H. (1997). Role of cardiac K-ATP channels during anoxia and ischemia. News Physiol. Sci. 12, 78-83.

Burgoyne, R. D. (1984). Mechanism of secretion from adrenal chromaffin cells. Biochem. Biophys. Acta. 779, 201-216.

Cena, V., Nicolas, G. P., Sanchez-Garcia, P., Kirpekar, S. M. and Garcia, A. G. (1983). Pharmacological dissection of receptorassociated and voltage-sensitive ionic channels involved in catecholamine release. Neuroscience 10, 1455-1462.

Challiss, R. A. J., Jones, J. A., Owen, P. J. and Boarder, M. R. (1991). Changes in inositol 1,4,5-trisphosphate and inositol 1,3,4,5-tetrakisphosphate mass accumulations in cultured adrenal chromaffin cells in response to bradykinin and histamine. $J$. Neurochem. 56, 1083-1086.

Cheek, T. R., O'Sullivan, A. J., Moreton, R. B., Berridge, M. J. and Burgoyne, R. D. (1989). Spatial localization of the stimulus-induced rise in cytosolic $\mathrm{Ca}^{2+}$ in bovine adrenal chromaffin cells: Distinct nicotinic and muscarinic patterns. FEBS Lett. 247, 429-434.

Cook, N. S. (1988). The pharmacology of potassium channel and their therapeutic potential. Trends Pharmacol. Sci. 9, 21-28.

Corcoran, J. J. and Kirshner, N. (1983). Inhibition of calcium uptake, sodium uptake, and catecholamine secretion by methoxyverapamil (D600) in primary cultures of adrenal medulla cells. J. Neurochem. 40, 1106-1109.

Edwards, G., Duty, S., Trezise, D. J. and Weston, A. H. (1992). Effects of potassium-channel modulators on the cardiovascular system. In Potassium channel modulators: Phamacological, molecular and clinical aspects (A. H. Weston, T. C. Hamilton, Ed.), pp. 369-463. Blackwell Science, Oxford.

Endoh, M. and Taira, N. (1983). Relationship between relaxation and cyclic GMP formation caused by nicorandil in canine mesenteric arteries. Naunyn-Schmiedeberg's Arch. Pharmacol. 322, 319.

Finta, E. P., Harms, L., Sevick, J., Fischer, H. D. and Illes, P. (1993). Effects of potassium channel openers and their antagonists on rat locus coerulus neurones. Br. J. Pharmacol. 109, 308-315.

Furukawa, K., Itoh, I., Kajiwara, M., Kitamura, K., Suzuki, H., Ito, Y. and Kuriyama, H. (1981). Effects of 2-nicotinamidoethyl nitrate on smooth muscle cells and on adrenergic transmission in guinea-pig and porcine mesenteric arteries. $J$. Pharmacol. Exp. Ther. 218, 260.

Garcia, A. G., Sala, F., Reig, J. A., Viniegra, S., Frias, J., Fonteriz, R. and Gandia, L. (1984). Dihydropyridine Bay-K-8644 activates chromaffin cell calcium channels. Nature 309, 69-71.

Goeger, D. E. and Riley, R. T. (1989). Interaction of cyclopiazonic acid with rat skeletal muscle sarcoplasmic reticulum vesicles. Effect on $\mathrm{Ca}^{2+}$ binding and $\mathrm{Ca}^{2+}$ permeability. Biochem. Pharmacol. 38, 3995-4003.

Hamilton, T. and Weston, A. (1989). Cromakalim, nicorandil and pinacidil: novel drugs which open potassium channels in smooth muscle. Gen. Pharmacol. 20, 1-9.

Hammer, R. and Giachetti, A. (1982). Muscarinic receptor subtypes: $M_{1}$ and $M_{2}$ biochemical and functional characterization. Life Sci. 31, 2992-2998.

Heldman, E., Levine, M., Rabeh, L. and Pollard, H. B. (1989). Barium ions enter chromaffin cells via voltage-dependent calcium channels and induce secretion by a mechanism independent of calcium. J. Biol. Chem. 264, 7914-7920.

Holzmann, S. (1983). cGMP as a possible mediator of coronary 
arterial relaxation by nicorandil (SG-75). J. Cardiovasc. Pharmacol. 5, 364-370.

Holzmann, S., Kukovetz, W. R., Braida, C. and Poch, G. (1992). Pharmacological interaction experiments differentiate between glibenclamide-sensitive potassium channels and cyclic GMP as components of vasodilation by nicorandil. Eur. J. Pharmacol. 215, $1-7$.

Ilno, M. (1989). Calcium-induced calcium release mechanism in guinea pig taenia caeci. J. Gen. Physiol. 94, 363-383.

Kukovetz, W. R., Holzmann, S., Braida C. and Poch, G. (1991). Dual mechanism of the relaxing effect of nicorandil by stimulation of cGMP formation and by hyperpolarisation. J. Cardiovasc. Pharmacol. 17, 627-633.

Ladona, M. G., Aunis, D., Gandia, A. G. and Garcia, A. G. (1987). Dihydropyridine modulation of the chromaffin cell secretory response. J. Neurochem. 48, 483-490.

Lim, D. Y. and Hwang, D. H. (1991). Studies on secretion of catecholamines evoked by DMPP and McN-A-343 in the rat adrenal gland. Korean J. Pharmacol. 27, 53-67.

Lim, D. Y., Kim, C. D. and Ahn, K. W. (1992). Influence of TMB-8 on secretion of catecholamines from the perfused rat adrenal glands. Arch. Pharm. Res. 15, 115-125.

Lim, D. Y., Park, G. H. and Park, S. H. (2000). Inhibitory mechanism of pinacidil on catecholamine secretion from the rat perfused adrenal gland evoked by cholinergic stimulation and membrane depoialrization. J. Auton. Pharmacol. 20, 123-132.

Masuda, Y., Yoshizumi, M., Ishimura, Y., Katoh, I. and Oka, M. (1994). Effects of the potassium channel openers cromakalim and pinacidil on catecholamine secretion and calcium mobilization in cultured bovine adrenal chromaffin cells. Biochem. Pharmacol. 47, 1751-1758.

Meisheri, K. D., Cipkus-Dubray, L. A., Hosner J. M. and Khan, S. (1991). Nicorandil-induced vasorelaxation: Functional evidence for $\mathrm{K}^{+}$channel-dependent and cyclic GMP-dependent components in a single vascular preparation. J. Cardiovasc. Pharmacol. 17, 903.

Murphy, K. P. and Greenfield, S. A. (1992). Neuronal selectivity of ATP-sensitive potassium channels in guinea-pig substantia nigra revealed by responses to anoxia. J. Physiol. (Lond) 453, 167-183.

Noma, A. (1983). ATP-regulated single K channels in cardiac muscle. Nature 305, 147-148.

Oka, M., Isosaki, M. and Yanagihara, N. (1979). Isolated bovine adrenal medullary cells: studies on regulation of catecholamine synthesis and release. In Catecholamines: Basic and Clinical frontiers (E. Usdin, I. J. Kopin, J. Brachas, Ed.), pp. 70-72. Pergamon Press, Oxford.

Perez-Vizcaino, F., Casis, O., Rodriguez, R., Comez, L. A., Garcia Rafanell, J. and Tamargo, J. (1993). Effect of the novel potassium channel opener, UR-8225, on contractile responses in rat isolated smooth muscle. Br. J. Pharmacol. 110, 11651171.

Petersen, O. H. and Maruyama, Y. (1984). Calcium-activated potassium channels and their role in secretion. Nature 307, 693-696.

Pierrefiche, O., Bischoff, A. M. and Richter, D. W. (1996). ATP- sensitive $\mathrm{K}^{+}$channels are functional in expiratory neurones of normoxic cats. J. Physiol. (Lond) 494, 399-409.

Quast, U. and Cook, N. S. (1989). Moving together: K+ channel openers and ATP-sensitive $\mathrm{K}+$ channels. Trends Pharmacol. Sci. 10, 431-435.

Schmid-Antomarchi, H., Amoroso, S., Fosset, M. and Lazdunski, M. (1990). $\mathrm{K}^{+}$channel openers activate brain sulphonylureasensitive $\mathrm{K}^{+}$channels and block neurosecretion. Proc. Natl. Acad. Sci. U.S.A. 87, 3489-3492.

Seidler, N. W., Jona, I., Vegh, N. and Martonosi, A. (1989). Cyclopiazonic acid is a specific inhibitor of the $\mathrm{Ca}^{2+}$-ATPase of sarcoplasimc reticulum. J. Biol. Chem. 264, 17816-17823.

Standen, N. B., Quatly, J. M., Davies, N. W., Brayden, J. E., Huang, Y. and Nelson, M. T. (1989). Hyperpolarizing vasodilators activate ATP-sensitive $\mathrm{K}+$ channels in arterial smooth muscle. Science 245, 177-1780.

Suzuki, M., Muraki, K., Imaizumi, Y. and Watanabe, M. (1992). Cyclopiazonic acid, an inhibitor of the sarcoplasmic reticulum $\mathrm{Ca}^{2+}$-pump, reduces $\mathrm{Ca}^{2+}$-dependent $\mathrm{K}^{+}$currents in guinea-pig smooth muscle cells. Br. J. Pharmacol. 107, 134-140.

Tallarida, R. J. and Murray, R. B. (1987). Manual of pharmacologic calculation with computer programs. 2nd Ed. SperingerVerlag, New York, pp. 132.

Terbush, D. R. and Holz, R. W. (1992). Barium and calcium stimulate secretion from digitonin-permeabilized bovine adrenal chromaffin cells by similar pathways. J. Neurochem. 58, 680687.

Uceda, G., Artalejo, A. R., Lopez, M. G., Abad, F., Neher, E. and Garcia, A. G. (1992). $\mathrm{Ca}^{2+}$-activated $\mathrm{K}^{+}$channels modulate muscarinic secretion in cat chromaffin cells. J. Physiol. 454, 213-230.

Uyama, Y., Imaizumi, Y. and Watanabe, M. (1992). Effects of cyclopiazonic acid, a novel $\mathrm{Ca}^{2+}$-ATPase inhibitor on contractile responses in skinned ileal smooth muscle. Br. J. Pharmacol. 106, 208-214.

Wada, A., Kobayashi, H., Arita, M., Yanagihara, N. and Izumi, F. (1987). Potassium channels in cultured bovine adrenal medullary cells: effects of high $\mathrm{K}$, veratridine and carbachol on 86rubidium efflux. Neuroscience 22, 1085-1092.

Wakade, A. R. (1981). Studies on secretion of catecholamines evoked by acetylcholine or transmural stimulation of the rat adrenal gland. J. Physiol. 313, 463-480.

Watson, S. and Abbott, A. (1991). Receptor Nomenclature Supplement. Trends Pharmacol. Sci. (Suppl), 31-33.

Weston, A. H., Longmore, J., Newgreen, D. T., Edwards, G., Bray, K. M. and Duty, S. (1990). The potassium channel openers: a new class of vasorelaxants. Blood Vessels 27, 306-313.

Weston, A. H., Southerton, J. S., Bray, K. M., Newgreen, D. T. and Taylor, S. G. (1988). The mode of action of pinacidil and its analogs P1060 and P1368: Results of studies in rat blood vessels. J. Cardiovasc. Pharmacol. 12 (Suppl), S10-S16.

Wu, C. W., Leung, C. K. and Yung, W. H. (1996). Sulphonylureas reverse hypoxia induced $\mathrm{K}^{+}$conductance increase in substantia nigra pars reticulata neurones. Neuroreport 7, 25132517. 